
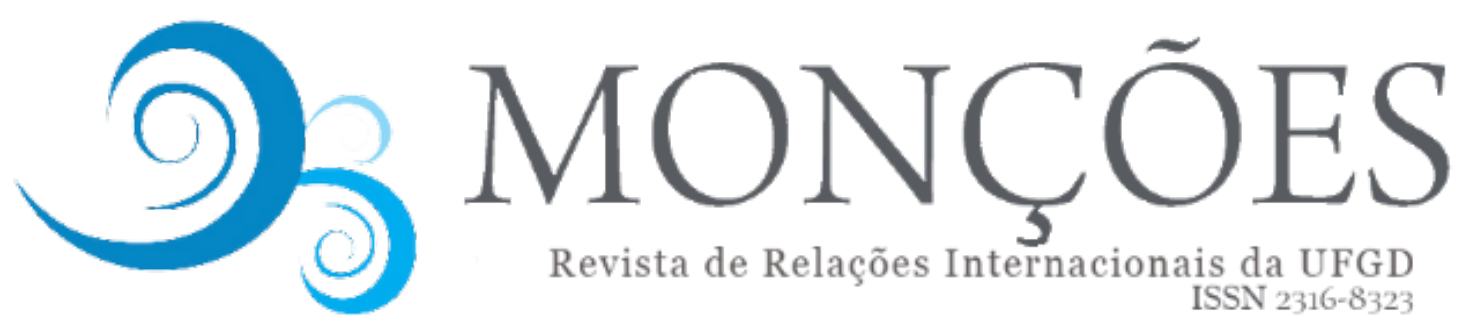

Revista de Relações Internacionais da UFGD

ISSN 2316-8323

\title{
PENSAMENTO COM TEORIA: ALTERNATIVAS PARA O CAMPO DE RELAÇÕES INTERNACIONAIS NO BRASIL E NA ÍNDIA
}

\author{
Luciano da Rosa Muñoz \\ Doutor em Relações Internacionais (UnB) e Professor de Política Externa Brasileira e \\ História das Relações Internacionais no Centro Universitário de Brasília (UniCEUB). E-mail \\ para contato: Imunoz1984@hotmail.com \\ Doutor em Relaç̃oses Internacionais (UnB), Pós-doutor em Direito (UERJ) e Professor de \\ Teoria das Relações Internacionais no Centro Universitário de Brasilia (UniCEUB). E-mail \\ para contato: raphael.spode@gmail.com
}

\begin{abstract}
RESUMO: Neste artigo, pretendemos delinear alternativas para o campo de Relações Internacionais no Brasil em um esforço comparativo com a realidade acadêmica indiana. Desde o princípio, tentamos submeter o projeto da assim chamada "Escola de Brasília" para o campo no Brasil à investigação crítica. Assim, defendemos que não é conveniente descartar totalmente as teorias de relações internacionais a fim de substituí-las pela construção de conceitos brasileiros aplicados ao campo. Em lugar disso, entendemos que seria mais complexo e rico abrir o campo ao diálogo crítico com tais teorias em uma via de mão dupla capaz de resgatar autores brasileiros clássicos com possíveis contribuições às Relações Internacionais. Na Índia, uma nova geração de acadêmicos de RI está atualmente defendendo o diálogo entre as teorias ocidentais e as tradições conceituais hinduístas. Eles querem evitar os reveses paroquiais envolvidos nas escolas nacionais de RI. Consideramos que podemos ter muito a aprender com eles se almejamos abrir o campo de RI no Brasil.
\end{abstract}

PALAVRAS-CHAVE: Teoria das Relações Internacionais; Giro decolonial; Sul Global.

\section{THOUGHT WITH THEORY: ALTERNATIVES TO THE FIELD OF INTERNATIONAL RELATIONS IN BRAZIL AND INDIA}

ABSTRACT: In this paper we intend to outline alternatives to the field of International Relations in Brazil in a comparative effort with the Indian academic reality. From the start we try to put the socalled "Brasília School" project to the field in Brazil into critical enquiry. Thus, we support that it is not convenient to discard the theories of international relations altogether in order to replace them by the construction of Brazilian concepts applied to the field. Rather we understand it would be more complex and richer to open our field to critical dialogue with such theories in a two way move able to restore classic Brazilian authors with possible contributions to International Relations. In India, a new generation of IR scholars is currently defending the dialogue between Western theories and Hindu conceptual traditions. They want to avoid the parochial setbacks involved in national schools of IR. We consider we may have much to learn with them if we aim at opening the Brazilian IR field.

KEYWORDS: International Relations Theory; Decolonial Shift; Global South. 


\section{Considerações iniciais}

No presente artigo, buscaremos defender o diálogo crítico entre teorias de relações internacionais e o pensamento próprio produzido em países periféricos tais como Brasil e Índia com base em um esforço de comparação do estado da arte dos campos acadêmicos de Relações Internacionais em ambos os locais. Inicialmente, partiremos da crítica ao projeto da "Escola de Brasília"1 para o campo, de acordo com o qual o cerne da almejada escola brasileira de Relações Internacionais deveria estar situado no rechaço completo das teorias em contraste à elaboração de conceitos brasileiros. Em compasso com o impacto do giro decolonial, contudo, buscaremos defender o diálogo entre o pensamento brasileiro e as teorias críticas de relações internacionais. Ao final, estaremos voltados ao cenário do campo na Índia. Conforme veremos, os indianos dividiram-se em duas gerações distintas de estudiosos das relações internacionais. Por um lado, a geração primitiva recusava as teorias hegemônicas em busca de uma escola nacional; por outro, a geração contemporânea entende que o diálogo é necessário e presume a disposição para buscar ferramentas de análise em sua própria bagagem cultural. Em nossa visão, caminho semelhante deve ser buscado entre nós - no campo de Relações Internacionais no Brasil.

Devemos destacar que este artigo constitui um desafio metodológico. Embora comparáveis, os cenários acadêmicos de Relações Internacionais no Brasil e na Índia apresentam cada qual suas peculiaridades. Como o leitor perceberá, no que se refere ao nosso caso, optamos por enfatizar a proposta da "Escola de Brasília" não porque a consideramos representativa do campo no Brasil como um todo, mas

\footnotetext{
1 As origens da "Escola de Brasília" remontam à constituição do primeiro curso de graduação de Relações Internacionais na Universidade de Brasília (UnB) na década de 1970. Em 1984, o programa de pós-graduação em Relações Internacionais da UnB foi criado no então Departamento de Ciência Política e Relações Internacionais. Dez anos depois, organizou-se o primeiro doutorado de História das Relações Internacionais. Em 2000, os dois programas foram fundidos e deram origem ao Instituto de Relações Internacionais (IREL/UnB), com crescente predomínio das abordagens historiográficas (LESSA, 2005, p. 38-39). Do ponto de vista acadêmico, portanto, tal divergência interdepartamental possa talvez explicar a animosidade da "Escola de Brasília" com as teorias de relações internacionais caras aos cientistas políticos. Em sua maioria, os integrantes da escola são historiadores. Por sua conta e risco, Saraiva (2008, p. 36-37) inclui no grupo nomes diversos como Amado Cervo, Paulo Roberto de Almeida, Moniz Bandeira, Clodoaldo Bueno, Wolfgang Döpcke e Norma Breda dos Santos. Além do próprio Saraiva, contudo, o autor central da "Escola de Brasília" é Amado Cervo. Por esse motivo, nossa análise estará centrada em suas obras, na medida em que delineiam deliberadamente o projeto da escola. A denominação "Escola de Brasília" é controversa. Assim, usaremos propositalmente as aspas. Em suma, parece-nos importante pensar o campo de Relações Internacionais no Brasil com referência a tal projeto, não apenas pela importância da Universidade de Brasília, senão também porque dessa instituição provêm os autores do artigo.
} 
apenas porque pretende sê-lo. Nesse sentido, o cerne do problema é a exclusão que busca efetivar do diálogo entre teorias de relações internacionais e conceitos oriundos do pensamento brasileiro com vistas a definir e congelar os estudos no país como se fosse de fato a escola brasileira de Relações Internacionais. Parecenos que cabe a comparação com a situação indiana. Como veremos, a tentativa de constituição de uma escola nacional naquele caso acabou por demonstrar-se tão somente a empreitada de uma geração tradicional de estudiosos, os quais foram posteriormente questionados criticamente por uma nova geração. Ora, o presente artigo é um esforço de aclarar semelhante movimento no Brasil. Assim, o diálogo entre teorias e pensamento próprio com viés descolonizador pode estar a caracterizar a emergência entre nós de uma nova geração de acadêmicos de Relações Internacionais.

Em ensaio publicado originalmente em 1923, Ortega y Gasset (1966, p. 145155), afirma que geração é um conceito importante, pois atesta as variações de sensibilidade vital de uma época para outra. A geração emergente comporia, assim, um novo corpo social íntegro formado por uma minoria seleta e pelas massas. De sua parte, caberia aos intelectuais seguir sua espontaneidade e romper com as ideias da geração precedente. Também parte daquela minoria, os homens de ação deveriam então implementar políticas públicas que os conectassem com a maioria da população. Na visão de Ortega y Gasset, os novos intelectuais estariam aptos a compreender as necessidades vitais do tempo presente de modo a decifrar a razão histórica e fazer previsões. Concordamos parcialmente com tal perspectiva. Em nossa visão, o conceito de geração é de fato importante, contudo, não o empregamos no presente artigo imbuídos da extensão das pretensões orteguianas. Quando, por comparação, discernimos novas gerações de intelectuais no campo de Relações Internacionais no Brasil e na Índia, queremos pôr em relevo, sobretudo em nosso país, por força da proximidade, tão somente algo como a ambiência de uma razão vital que perpassa autores contemporâneos diversos.

De modo algum, buscamos profetizar, tampouco deslindar algum movimento do devir histórico. Menos ainda, tentamos representar as massas ou iluminar decisões políticas dos dirigentes. Como lembra Spivak (2010, p. 58-65), o intelectual pós-colonial - e talvez não possa ser outra nossa condição - entende que seu privilégio é sua perda, pois deveria compor com as massas subalternizadas, mas faz parte da elite ou minoria seleta. Dessa forma, deve estar sempre pronto ao saudável 
exercício da autocrítica. Conforme veremos na sequência, o projeto da "Escola de Brasília" propôs-se a constituir uma escola brasileira de relações internacionais cujo elemento crucial era a exclusão do aporte trazido pela reflexão teórica ao campo. Nesse caso, a tentação de erguer uma escola nacional desdobrou-se na vontade de desvendar a razão histórica e perpetuar-se no tempo. Em contrapartida, aplicamos com cautela o conceito de geração, não apenas para sinalizar que a empreitada de uma escola pode de fato vir a configurar no tempo presente uma geração passada, senão também para indicar muito tentativamente algo como uma nova geração entre nós, preocupada com a descolonização do campo de Relações Internacionais, porém também permeada por abordagens dessemelhantes entre si.

Dessa forma, o presente artigo está dividido nas três seções que seguem. Inicialmente, abordaremos criticamente o projeto da "Escola de Brasília", tendo maior atenção voltada ao modo mutuamente excludente como relaciona conceitos vindos do pensamento brasileiro e teorias de relações internacionais. Na segunda seção, defenderemos o diálogo crítico entre essas duas ferramentas, de maneira a pensar o entre-lugar que ocupam não apenas o intelectual pós-colonial em geral, mas também alguns trabalhos da atual geração de acadêmicos de Relações Internacionais entre nós. Assim, parece-nos que, apesar de suas diferenças, trazem novos olhares a respeito de autores brasileiros clássicos, assim como de matrizes nossas não europeias de pensamento, mantendo porém a preocupação de dialogar com as teorias críticas do campo em uma via de mão dupla. Por fim, apresentamos o percurso que o campo teve na Índia. Nesse caso, almejamos delinear um cenário de comparação e inspiração para os estudos entre nós, assim como apresentar ao leitor brasileiro autores indianos pouco conhecidos no Brasil. Veremos como, naquela situação acadêmica, a proposta de uma escola nacional de Relações Internacionais revelou-se um projeto datado de uma geração tradicional de intelectuais, posteriormente colocada sob escrutínio crítico em função das distintas necessidades de tempos outros.

\section{Pensamento sem teoria}

Em artigo publicado em 2008, Amado Cervo defende diminuir o papel das teorias no campo de Relações Internacionais no Brasil, bem como seu prestígio nos 
programas de ensino acadêmico no país, sob o argumento de que não explicam adequadamente problemas de escopo nacional ou regional. Em seu lugar, argumenta pela necessidade da construção de conceitos brasileiros, os quais teriam por função banir o imperialismo epistemológico das teorias de relações internacionais de origem anglo-americana. Por detrás de sua pretensão por universalidade, as teorias estariam mascarando interesses específicos dos Estados hegemônicos e contribuindo para a promoção da desigualdade entre as nações. De modo a evitar tais armadilhas do conhecimento, Cervo entende que o meio acadêmico do campo de Relações Internacionais no Brasil deve rechaçar as teorias e voltar-se para a elaboração de conceitos brasileiros capazes de influenciar a formação mental e profissional dos dirigentes e estimular o desenvolvimento e o bem-estar nacionais (CERVO, 2008a, p. 8-22).

Esse projeto de definição da identidade e da agenda do campo no Brasil retoma e elabora sua hipótese anterior do pensamento sem teoria. Seu raciocínio presume a oposição marcada entre teoria e história, consideradas estratégias incompatíveis para o estudo das relações internacionais. Por um lado, a teoria dos cientistas políticos parte da dedução do conhecimento e busca a chave de explicação da realidade internacional; por outro, os historiadores partem de acumulado obtido em pesquisa empírica, o qual é analisado de modo indutivo. Sob influência da Escola Francesa de História das Relações Internacionais, entende Cervo que é preferível adotar a abordagem dos últimos, pois é mais flexível e não busca desvendar leis, senão apenas regularidades históricas. Com base nisso, critica a hegemonia do realismo durante a Guerra Fria, na medida em que, porque oriundo do mundo anglo-americano, nada tinha a dizer sobre a realidade dos países do Terceiro Mundo. Entretanto, não descarta apenas o realismo. Em sua visão, as teorias da dependência, cuja origem é brasileira e latino-americana, não devem ser reconhecidas como teorias das relações internacionais (CERVO, 1994, 13-17).

Como consequência, Cervo reduz a agenda do campo de Relações Internacionais no país à preocupação historiográfica com a construção de conceitos brasileiros aptos a guiar a ação dos agentes responsáveis pela formulação e execução da política externa. Do ponto de vista acadêmico, tal também é o cerne para a pretensão de delimitar uma escola nacional ou regional de Relações Internacionais. Nesse sentido, afirma Saraiva (2008, p. 35-39) que Brasil e Argentina são os países sul-americanos que possuem abordagens sistemáticas da história das 
relações internacionais. Seus aspectos comuns são a influência da mencionada escola francesa, a ênfase no tema do desenvolvimento e o entrosamento entre historiadores dos dois países, o que permitiria caracterizar tais esforços como as bases de uma escola brasileiro-argentina de Relações Internacionais. Do lado brasileiro, o chamado grupo de Brasília, centrado em Amado Cervo, contribuiu não apenas para superar a antiga história diplomática por meio da diversificação das fontes de pesquisa, mas também para compreender a inserção internacional do Brasil desde o século XIX. Em depoimento recente, afirma Cervo (2018, p. 21-22) que há uma "Escola de Brasília" que pode mesmo ser identificada a uma escola brasileira de Relações Internacionais, cujo diferencial seria exatamente o confronto entre teorias e conceitos; cujo projeto seria fulminar as teorias de relações internacionais no Brasil.

Em sua proposta para pensar teorias de relações internacionais alternativas, Acharya (2011, p. 622-624) parte de uma constatação presente em Cervo, segundo a qual é falso o caráter universal de realismo e liberalismo, uma vez que são construções teóricas que não dão conta de experiências e vozes não ocidentais. Entretanto, acrescenta Acharya que escolas nacionais ou regionais de Relações Internacionais podem tornar-se camisas de força que obstaculizam análises plurais e dialógicas no campo. Em sua visão, isso ocorre quando tais escolas funcionam como centros de racionalização da ascensão e queda de seus respectivos países. Passados pouco mais de dez anos após a publicação do artigo de Cervo contra as teorias, parece-nos importante destacar tal ressalva crítica. Em 2008, ele defendia a primazia dos conceitos brasileiros em compasso ao projeto de contrapoder dos países emergentes - tais como Brasil e Índia - cuja voz era cada vez mais ouvida em foros multilaterais, por exemplo o G-20 da OMC (CERVO, 2008a, p. 11). Quer dizer, colocava-se na posição de quem buscava compreender e influenciar a formação mental dos dirigentes e a formulação da política externa na era da diplomacia ativa e altiva de Lula da Silva e Celso Amorim.

Em nossa visão, a repercussão do projeto de Cervo e Saraiva para a "Escola de Brasília" dependeu da ascensão e queda dessa política externa, oscilação que hoje é bastante visível. Não por acaso, Cervo e Lessa (2014, p. 133-134) atrelaram o declínio da inserção internacional do Brasil durante o governo Dilma Rousseff à inexistência em sua gestão de conceitos capazes de movimentar Estado e sociedade em torno da política externa. É possível supor, à falta de conceitos 
construídos por essa escola brasileira de Relações Internacionais. Assim, consideramos problemática a associação da atividade acadêmica de elaboração conceitual à formulação e execução da política externa, sejam de quais governos forem. Concordamos com Acharya (2011, p. 632-633), segundo quem os esforços de escolas regionais ou nacionais correm o risco de incorrer em paroquialismo. Não nos parece ser outro o cerne da proposta de Cervo quando propõe fulminar as teorias de relações internacionais. Aqui, o rechaço de realismo e liberalismo acaba apenas por substituir o paroquialismo global-norte-americano da disciplina de Relações Internacionais por outro regional-brasileiro. Desse modo, seus movimentos estão relacionados: por um lado, disciplinar o campo no país e circunscrevê-lo à construção de conceitos brasileiros; por outro, elaborá-los a fim de influenciar decisões de poder. É possível pensar, contudo, caminhos alternativos.

Para Cervo, seria necessário descartar não apenas as teorias hegemônicas tais como realismo e liberalismo - sob o argumento de sua parcialidade, senão também todas as vertentes teóricas críticas oriundas do "terceiro debate" (LAPID, 1989). Nesse passo, seu argumento assume outras feições. O descarte das teorias críticas seria necessário em razão do estado caótico a que a reflexão teórica teria ingressado desde então nos círculos acadêmicos do mundo anglo-americano. Seu rebate não vai mais longe, contudo, do conhecimento do construtivismo de Alexander Wendt, segundo ele uma mélange das contradições da teoria incapaz de resolver a confusão mental reinante. Por sua vez, Cervo tampouco se abstém em confundir o leitor, quando considera que um conjunto de conceitos sem ser uma teoria pode ser comparado a uma teoria e exercer funções idênticas (2008a, p. 913). Quando descarta as teorias críticas, não considera que sua própria crítica à parcialidade das teorias hegemônicas é assunto antigo. Concordamos com Luciano (2013, p. 81), de acordo com quem Cervo apresenta uma visão reducionista sobre o atual estágio do debate teórico, o que o leva a ignorar o aporte das abordagens póspositivistas - teoria crítica, pós-estruturalismo, feminismo e pós-colonialismo. Em consequência, sua oposição entre teorias e conceitos incorre em um sectarismo acadêmico que deve ser evitado.

Em artigo de 1987, na vertente do pós-estruturalismo, Walker já havia salientado as mesmas críticas de Cervo às teorias do mainstream. Em seu entendimento, o neo-realismo de Kenneth Waltz deveria ser problematizado com base na questão da mudança histórica, uma vez que seu método positivista 
pressupunha compreender as relações internacionais através de uma estrutura atemporal. A principal contribuição de Walker é pôr em questão a própria dicotomia entre estrutura e história - ou entre teorias e conceitos -, oposição simples que norteia todo o argumento de Cervo em sua investida contra as teorias de relações internacionais. Por um lado, entende que o estruturalismo não lida bem com a diversidade e a diferença; por outro, não compreende que a solução para o problema do realismo político - e, acrescentemos nós, para o campo de Relações Internacionais - signifique afirmar que as estruturas não têm importância. Assim, considera necessário manter aberta a tensão - e o diálogo - entre estrutura e história para evitar um dualismo maniqueísta (WALKER, 1987, p. 81-82). Em seu descarte intransigente das teorias, não estaria Cervo apenas revertendo uma polarização excludente e cerrando o campo à diversidade no Brasil?

De um lado, afirma Luciano (2013, p. 78-80) que a maioria dos teóricos não ocidentais é treinada em escolas ocidentais - tal como foi o caso de Amado Cervo, cuja formação acadêmica ocorreu na França; de outro, entende que Cervo revaloriza os conceitos como instrumento descolonizador contra o imperialismo epistemológico das teorias do Primeiro Mundo. Parece-nos necessário qualificar tais afirmações. Em primeiro lugar, não consideramos que Cervo efetiva um movimento descolonizador, pois seu projeto não implica problematizar a formação do Estado e da sociedade brasileiros à luz da relação entre colonialidade e modernidade na América Latina. De acordo com Quijano (1992, p. 11-14), o colonialismo foi um sistema de dominação direta dos europeus sobre os demais continentes, o qual já está derrotado enquanto mecanismo formal. No entanto, a colonialidade - a outra face da modernidade permaneceu por meio de discriminações nacionais, sociais, raciais e étnicas ainda existentes dentro e fora das sociedades latino-americanas. Por sua vez, a colonialidade cultural continuou impondo às regiões periféricas seus padrões ocidentais para gerar conhecimento, assim como a sedução exercida pela cultura europeia ainda é requisito para obtenção pelas elites locais do acesso ao poder. Dessa forma, um movimento efetivo de descolonização epistemológica deveria desenraizar o eurocentrismo em suas fundações presentes em nosso próprio modo de conhecer.

Conforme Quijano (2000, p. 550-556), o primeiro problema do eurocentrismo para a América Latina é sua concepção linear de História. Na América Latina, por exemplo, jamais as formas de trabalho "pré-capitalistas" - escravidão africana e 
servidão indígena - foram incompatíveis com o capitalismo. Essa simultaneidade entre o arcaico e o moderno é algo que singulariza nossa formação histórica e demandaria olhar com suspeita o eurocentrismo imbricado em abordagens lineares e gradualistas tais como aquelas que privilegiam a modernização e o desenvolvimento. Para Quijano, o segundo problema do eurocentrismo é o dualismo gerador de uma concepção excludente de espaço. Com base no dualismo cartesiano entre corpo e alma, a modernidade europeia formulou a si própria como o espaço da racionalidade e da civilização, ao passo que o espaço de fora da Europa foi entendido como aquele do estado de natureza. Através dessa bipartição, a colonialidade penetrou na América Latina por meio da associação assimétrica da natureza a negros e indígenas, com base na qual se obtinha legitimação para o racismo e a opressão do trabalho. Dessa forma, no espelho do eurocentrismo, o latino-americano vê sua imagem distorcida, pois temos muito da Europa, mas também somos muito diferentes dela.

Nesse sentido, não há efeito descolonizador em Relações Internacionais em uma proposta incapaz de problematizar a linearidade histórica e o dualismo espacial. A crença na linearidade histórica investe nas promessas da abordagem desenvolvimentista; por sua vez, o dualismo excludente mascara a colonialidade e o racismo por meio de um estatocentrismo voltado ao espaço da política externa, porém cego aos condicionantes políticos, econômicos e sociais internos. Para Cervo (2008a, p. 13), a ousadia está em descartar as teorias e limitar-se a erguer conceitos brasileiros aplicados às relações internacionais. Em que pesem suas intenções, contudo, parece-nos que sua ousadia alça voo rasteiro. Do ponto de vista do projeto decolonial, Cervo não consegue desprender-se do eurocentrismo. Assim, não põe em questão a visão linear da História. Em seu entendimento, há um acumulado histórico na política externa brasileira, conjunto de princípios e valores sedimentados gradual e progressivamente ao longo do tempo, entre os quais inclui o vetor do desenvolvimento a partir de 1930. Além disso, reifica o Estado nacional e a dualidade entre os âmbitos interno e externo. Considera Cervo que as transições de regime político não impactam a política externa, assim como situa o Estado no centro de seus conceitos brasileiros fundamentais, os paradigmas liberalconservador, desenvolvimentista, neoliberal e logístico (CERVO, 2008b, p. 26-90).

Em nossa visão, seu eurocentrismo impede-o de problematizar a colonialidade na experiência histórica brasileira, inclusive na articulação complexa 
entre nosso tipo de sociedade excludente e a constituição elitista do corpo diplomático, encarregado de formular e executar a política externa. Ironicamente, Cervo defende-se dos centros hegemônicos por meio da elaboração de mais um dualismo - entre teorias e conceitos - o qual também desnuda as bases frágeis e eurocêntricas de seu projeto enquanto projeto descolonizador. Em outras palavras, Cervo enxerga a realidade brasileira pelo reflexo de sua formação acadêmica francesa. Na França, conforme destaca Wæver (1998, p. 708-709), a disciplina de Relações Internacionais formou-se com agenda intelectual separada e autônoma do imperialismo acadêmico dos Estados Unidos na Guerra Fria. Contra a teorização universal norte-americana, os franceses buscavam sua especificidade cultural com ênfase no uso de conceitos. Assim, surgiu a escola francesa de História das Relações Internacionais a partir da velha história diplomática e da inspiração vinda da Escola dos Annales. Em grande medida, portanto, o projeto da escola brasileira de Relações Internacionais é uma transposição do modelo francês, cujos ataques às teorias anglo-americanas pouco fazem avançar a agenda decolonial.

\section{Teorias e conceitos: diálogo crítico}

De acordo com Jatobá (2013a, p. 41-44), os acadêmicos brasileiros apresentam duas atitudes em face das teorias de relações internacionais. Por um lado, utilizam sem questionamento as tradições ortodoxas do realismo e do liberalismo, o que acarreta uma postura de conformismo. Por outro, descartam-nas voltados à busca por perspectivas nacionais embasadas em conceitos. Como vimos, Cervo defende essa última estratégia. Concordamos com Jatobá, contudo, quando afirma que nenhuma das duas alternativas é adequada. Nesse sentido, não satisfaz o mero consumo irrefletido das teorias made in USA, tampouco sua substituição total e intransigente por conceitos brasileiros. Uma em cada extremo, as duas estratégias são paroquialismos inversos que se tocam. Parece-nos mais acertada a posição de Jatobá, segundo quem é preciso manter aberto um diálogo crítico entre teorias e conceitos. Antes que se procure descartar as teorias, é importante conhecer seus desdobramentos mais recentes, tais como pós-estruturalismo, feminismo e póscolonialismo. Dentro do giro decolonial na América Latina, por sua vez, Mignolo (2007, p. 450-463) propõe o desprendimento epistêmico (epistemic de-linking) dos 
padrões de conhecimento ocidentais com base em fundamentada crítica não apenas da teoria crítica e do pós-estruturalismo, mas também do próprio pós-colonialismo. Essa atitude de descolonização da mente parte da premissa presente em Quijano, segundo quem a modernidade europeia não pode ser compreendida sem sua vinculação com a colonialidade existente no continente americano desde 1492. Como consequência, defende Mignolo a pluriversalidade como projeto universal em resistência à totalidade totalitária embasada apenas no conhecimento ocidental. Entretanto, parece-nos importante salientar que Mignolo não advoga a hipótese do descarte, pois entende que as fundações ocidentais do conhecimento são a um só tempo perigosas e inevitáveis. Assim, o desprendimento epistêmico pressupõe um diálogo crítico a ser realizado por meio de um pensamento fronteiriço (border thinking) entre a hegemonia ocidental e saberes que resistem ao silenciamento, por exemplo, através da revalorização de autores locais.

Entendemos que Cervo acerta quando busca revalorizar autores brasileiros clássicos e trazê-los para o campo de Relações Internacionais. Menciona a importância de intérpretes do Brasil, tais como Manoel Bomfim e Gilberto Freyre, além de intelectuais modernistas e de isebianos históricos, respectivamente, Oswald de Andrade e Helio Jaguaribe (CERVO, 2008a, p. 14-15). Questionamos, porém, sua dificuldade em colocar tais autores em diálogo crítico com as teorias de relações internacionais, o que ironicamente reforça sua posição periférica pois considera-os apenas construtores de conceitos brasileiros. Por que tais autores não poderiam teorizar criticamente sobre o cenário global? Ao contrário de Cervo, Jaguaribe (2013, p. 15-20) reconhece a relevância das teorias da dependência em suas formulações acerca do relacionamento entre centro e periferia. No entanto, não compartilha das conclusões da abordagem marxista, segundo a qual não há possibilidade de superação da dependência dentro do sistema capitalista global. Em sua visão, a maioria das elites periféricas comporta-se de modo disfuncional, pois se associa aos interesses das elites centrais e mantém as condições de dependência internacional em troca da manutenção de seus privilégios sociais no âmbito doméstico. Em condições apropriadas, contudo, entende Jaguaribe que parte das elites periféricas pode mobilizar seus povos e reagir de maneira exitosa contra a situação de dependência.

Também distinto a Cervo, parece-nos que Jaguaribe propõe o diálogo crítico entre as culturas hegemônica e dependente. Com base em sua leitura de Toynbee, 
apresenta duas categorias aptas a explicar esse encontro colonial a partir das relações entre as culturas helênica e judaica na Antiguidade. Por um lado, o zelotismo é uma reação ortodoxa e radical destinada a rejeitar a cultura da civilização conquistadora; por outro, o herodianismo parte da percepção de que tal civilização é superior, o que implica aceitar suas formas de pensamento. Como podemos perceber, essas duas atitudes extremas são análogas àquelas descritas por Jatobá quando pontua a situação dos acadêmicos brasileiros vis-à-vis as teorias de relações internacionais. Assim, os extremos também não são adequados: no zelotismo indica desespero; no herodianismo, perda de identidade. Para Jaguaribe, a relação entre esse par oposto é fundamental para podermos pensar a relação entre o par autonomia-dependência. Quando se volta para a experiência da América Latina, afirma que prevaleceu um herodianismo processado de modo alienado, uma vez que nossas elites eram disfuncionais e mais identificadas com a cultura europeia do que com seus próprios povos (JAGUARIBE, 2013, p. 20-37).

Reverter a postura de herodianismo alienado seria indispensável para tratar do problema das elites disfuncionais na América Latina e gerar condições históricoculturais de superação da dependência. Como fazê-lo? De acordo com Jaguaribe (2013, p. 37-51), o reconhecimento dos elementos não ocidentais - indígenas e africanos - presentes na composição cultural dos países da região teria peso decisivo para que a estratégia do herodianismo fosse bem-sucedida e concretizada com sentimento nacional e responsabilidade social. Assim, com base de comparação no caso japonês, defende o herodianismo seletivo como uma postura de meio-termo entre os extremos, em que a um só tempo incorporam-se aspectos da cultura hegemônica e o núcleo central da própria cultura é mantido. Em nosso argumento, devemos enfatizar dois pontos. Primeiramente, parece-nos que a proposta de Jaguaribe não pode efetivar-se no campo de Relações Internacionais no Brasil sem a disposição a manter aberto o diálogo crítico entre teorias e conceitos. Dessa forma, entendemos que Cervo incorre tanto em zelotismo quanto em herodianismo extremos quando veta esse caminho e insiste no dualismo simples respectivamente, quando descarta as teorias anglo-americanas e aceita o modelo historiográfico francês. É possível afirmar que Cervo assim o faz exatamente porque seu projeto não é de fato descolonizador, já que não inclui as matrizes indígena e africana à sua ideia de núcleo cultural brasileiro com vistas a poder problematizar as condicionantes espaço-temporais do eurocentrismo. 
Além disso, parece-nos que a "Escola de Brasília" incorre não apenas em uma interpretação triunfalista de Jaguaribe, senão também - por assim dizer - em uma leitura demasiadamente institucional de sua obra. Em Saraiva (2014, p. 9-16), Jaguaribe não é descrito como alguém capaz de teorizar, mas como um construtor de conceitos que inaugurou o sentido universalista do conceito brasileiro de autonomia. Embora reconheça que a autonomia passou por ressignificações ao longo da história da política externa brasileira, entende Saraiva que há um núcleo comum que aproxima os desafios enfrentados pelo país desde o Império até o século XXI. Nesse sentido, reitera a narrativa diplomática oficial segundo a qual a política externa não sofre abalos de origem doméstica. Por sua vez, Jaguaribe ocupa em sua visão a posição honrosa de precursor do universalismo da Política Externa Independente (PEI), considerada pelo Itamaraty um dos marcos fundacionais da diplomacia brasileira. Desde uma postura crítica, é importante desmistificar a aura que envolve conceitos brasileiros tal como a autonomia. Assim, Jaguaribe também pode ser entendido como um intelectual que apontou e criticou a incapacidade de o Itamaraty atualizar-se no final da década de 1950 em compasso com o novo significado que a autonomia assumia como parte de um projeto nacional de desenvolvimento (MUÑOZ, 2016, p. 217-219).

Na concepção de Dussel (2016, p. 61-67), o primeiro passo para libertar do silenciamento as culturas pós-coloniais - tal como a brasileira e latino-americana - é negar o desprezo de si e afirmar sua exterioridade. Não basta, contudo, tal afirmação; é preciso também poder fazer a crítica de sua própria cultura com emprego seletivo das ferramentas teóricas modernas. Assim, entende Dussel que o intelectual crítico no ou do mundo pós-colonial está localizado entre sua cultura e a cultura moderna hegemônica. Cervo ensaia o movimento de afirmação, porém não consegue ou não quer situar-se na incômoda e inquietante posição de in-betweenness (LISLE, 2016), lugar onde ocorre não apenas o diálogo crítico entre teorias e conceitos, mas também a autocrítica do intelectual. Situar-se nesse entre-lugar implica contestar as interpretações canônicas de conceitos brasileiros aplicados às relações internacionais, assim como permitir-se teorizar para levar a frente uma analítica crítica do poder. Nesse sentido, entende Ballestrin (2013, p. 108-109) que o processo de descolonização do pensamento não deve ser confundido com a rejeição da criação humana realizada pelo Norte Global. Em lugar disso, trata-se de revalorizar as práticas, experiências, conceitos e teorias do Sul Global como 
contraponto à histórica divisão do trabalho intelectual entre as duas regiões. Assim, a partir do diálogo entre construções teóricas contra-hegemônicas ocidentais - tais como as correntes do pós-positivismo em Relações Internacionais - e o conhecimento subalternizado do Sul Global, torna-se possível não apenas descolonizar a teoria, mas o próprio poder.

Dessa forma, afirma Jatobá (2013b, p. 119-122) que esse teorizar crítico implica reconhecer não somente que a realidade política pode comportar diversas perspectivas, senão também que o campo de Relações Internacionais deve abrir-se às contribuições transdisciplinares da filosofia e das ciências sociais. Em nosso entendimento, portanto, três movimentos podem caracterizar esse diálogo crítico entre teorias e conceitos no que concerne ao Brasil: (1) trazer ao campo aportes de autores brasileiros clássicos de áreas diversas do conhecimento por meio de interpretações alternativas; (2) colocá-los em contato com as teorias em uma via de mão dupla com os conceitos oriundos de seu pensamento brasileiro; (3) refletir acerca da problematização de dicotomias tais como centro/periferia, tradicional/moderno e interno/externo.

Além das possibilidades abertas pela obra de Helio Jaguaribe, podemos apontar esforços nesse sentido na leitura feita por Selis (2018, p. 186-191) da obra de Oswald de Andrade e dos atuais "intérpretes da antropofagia", tais como Viveiros de Castro e Silviano Santiago. Considera a autora que a antropofagia catalisa uma "ruptura radical com os papéis do jogo moderno da alteridade, de modo que, através dela, o inimigo reaparece como positividade transcendental." Assim, configura uma contra-ontologia que inverte a centralidade do sujeito moderno e ocidental. Mais do que isso, Selis coloca a antropofagia ao lado das teorias da dependência e do giro decolonial como ferramentas capazes de descolonizar epistemologicamente a disciplina de Relações Internacionais e abrir um flanco de infiltração clandestina para o pensamento latino-americano. Por sua vez, Urt (2016) propõe-se a analisar as contribuições da visão de mundo indígena - em específico, dos povos Guarani e Kaiowá - em diálogo crítico com a própria teoria de relações internacionais. Nesse passo, destaca o autor como o Estado brasileiro foi reconhecido como autônomo e civilizado no espaço internacional por meio da consecução da guerra contra os indígenas exteriorizada por práticas de colonialismo interno e de despossessão de terras. De sua parte, a resistência dos Guarani Kaiowá questiona o paradigma moderno de soberania, pois não apenas não concebe o território como espaço 
excludente, mas como espaço de relações, senão também mantém a conexão entre política e espiritualidade perdida na experiência ocidental.

Da mesma forma, podemos destacar interpretações marginais de outros dois autores brasileiros clássicos: Florestan Fernandes e Rui Barbosa. No primeiro caso, Lage (2019) procura desafiar a divisão global do trabalho intelectual, segundo a qual os países centrais devem produzir teoria e os países periféricos apenas aplicá-las localmente e fornecer dados empíricos para explicação. Não se trata, contudo, de erguer um muro entre conceitos locais e teorias globais, senão de pensar uma via de mão dupla. Assim, Lage entende que obras clássicas de interpretação do Brasil podem ser lidas como teorizações não apenas com valor local, mas com potencial crítico ao próprio capitalismo global. Consequentemente, quando Florestan Fernandes pensa o capitalismo dependente brasileiro como uma coexistência entre arcaico e moderno, a narrativa histórica linear de modernização dos países centrais é colocada sob suspeita. Por sua vez, Spode (2017) interpreta alternativamente a obra de Rui Barbosa. Em sua visão, devem ser ressaltados tanto os aspectos religiosos de seu pensamento acerca da política internacional quanto seu engajamento no debate de ideias ao tempo da Primeira Guerra Mundial. Dessa forma, Spode põe em suspenso a dicotomia entre razão e emoção e abre a possibilidade de se atravessar criticamente a contribuição de Rui Barbosa ao "primeiro debate" polarizado entre realismo e idealismo.

Nesse sentido, parece-nos que autores como Jatobá, Selis, Urt, Lage, Spode e Muñoz - entre outros que a carência de espaço nos impede de mencionar podem estar neste momento configurando uma nova geração de estudos no campo de Relações Internacionais no Brasil. Evidentemente, cada autor tem seu próprio ponto de vista. Há, contudo, uma preocupação central em reler alternativamente autores brasileiros clássicos e tradições marginais de pensamento e colocá-los em diálogo crítico com a teoria de relações internacionais a fim de buscar descolonizar a disciplina e desestabilizar suas dicotomias. Além disso, há interessantes paralelos nesses estudos. Por exemplo, a preocupação de Urt em reconectar política e espiritualidade por meio do estudo dos povos Guarani e Kaiowá reaparece em Spode em sua análise alternativa de Rui Barbosa. Ou ainda, a extensão em que o pensamento indígena no Brasil precariza a própria ideia de autonomia do Estado brasileiro - exercida à base de exclusão interna - retorna de alguma forma na leitura crítica que realiza Muñoz (2019) do conceito de autonomia na política externa 
brasileira. Nesse último caso, o autor busca analisar o debate de autonomia no Brasil a partir de uma interpretação genealógica, a qual possibilite colocar em questão tanto a divisão espacial entre as políticas interna e externa, quanto a interpretação corrente segundo o qual a história da política externa do Brasil perfaz uma linha de suave continuidade ao longo do tempo, imperturbada por oscilações domésticas.

Por essas razões, precisamos não apenas combater a hipótese de Cervo contra as teorias, mas também as pretensões da "Escola de Brasília" a enclausurar e definir o campo de Relações Internacionais no Brasil. A bem da verdade, não se trata de uma escola, mas de uma geração tradicional de acadêmicos. De outra parte, conforme adiantamos, o conceito de geração é aplicado aqui com a devida cautela. Entre os últimos autores citados, parece-nos haver uma ambiência vital comum em direção ao movimento de descolonização do campo de Relações Internacionais por meio do resgate de autores clássicos e tradições de pensamento brasileiros. Entretanto, salientemos que cada trabalho é também um universo próprio. Além disso, não se trata em absoluto de endeusar o potencial crítico do giro decolonial. Como pontua Ballestrin (2013, p. 111-112), em saudável exercício de autocrítica, a proposta decolonial também possui limitações, tais como a tendência à romantização dos oprimidos e explorados, o desconstrutivismo paralisante e a dificuldade de efetivar o movimento descolonizador sem abandonar as contribuições do pensamento ocidental. Por ora, o que podemos afirmar é a emergência de um debate intergeracional no Brasil: por um lado, há a segurança dogmática buscada pela constituição de uma escola nacional; por outro, a liberdade (auto)crítica de uma geração de entre-lugar - quem sabe de entre-tempo. Conforme veremos na sequência, esse embate entre gerações distintas já constitui um elemento consolidado da situação do campo na Índia, o qual tomamos como parâmetro de comparação.

\section{O contexto abrangente da produção do conhecimento em Relações Internacionais na Índia}

Bajpai (2005, p. 23-24) e Shahi (2016) descrevem a história da institucionalização das Relações Internacionais na Índia como um processo intenso 
e transformador. De acordo com os autores, o marco inicial desse processo esteve associado ao surgimento do Indian Council of World Affairs (ICWA), em 1943, apesar da pesquisa e o ensino sistematizados na área progredirem efetivamente com a formação da Indian School of International Studies (ISIS), em $1955 .^{2}$ Mais tarde, o escopo dessa escola teria se ampliado quando a ISIS - que inicialmente fazia parte da Delhi University - uniu-se com a Jawaharlal Nehru University, sendo rebatizada como School of International Studies (SIS), em 1970, outro importante marco do campo. Presentemente, haveria um arranjo eclético de cursos de Relações Internacionais, organizados em outras localidades do país (SHAHI, 2016; BAYLY, 2017, p. 5). ${ }^{3}$

Apesar do aparente sucesso, por um período após a sua independência (1947), os estudos internacionais na Índia foram marginalizados e enfrentaram problemas relativos ao foco e reconhecimento acadêmico. Ao mesmo tempo em que campos como a economia, a antropologia e as ciências sociais prosperaram a nível mundial, o campo foi interpretado como uma forma inferior de ciência social e não conseguiu angariar posicionamento nos departamentos de Ciência Política do país. Com raízes que deitam origens no impulso administrativo de Nehru, esse período é marcado pela fragilização e uma concentração da pesquisa na capital do país (BAJPAI, 2005; BEHERA, 2007; SAHNI, 2009). ${ }^{4}$

Para Shahi (2016) esse quadro retrata a "primeira fase" do campo na Índia. Essa fase, denominada de "primitiva" (1938-1969) ${ }^{5}$, define-se pelos estudos de área

\footnotetext{
2 De acordo com Bayly (2017, p. 2-3), antes da década de 40, existiram pioneiros que elaboraram contribuições seminais, como por exemplo, M. N. Chatterjee e o sociólogo bengali Benoy Kumar Sarkar. O trabalho de Sarkar procurou combinar as tradições intelectuais do sul asiático com a nascente disciplina de Relações Internacionais. Um artigo publicado em 1919, Hindu Theory of International Relations, recupera o pensamento de Kautilya e Kamandakiya Nitisara. Combinando-os com a doutrina da mandala, apresenta uma noção hindu de equilíbrio de poder (SARKAR, 1919, pp. 400-414).

${ }^{3}$ Para além de numerosas universidades públicas, privadas e internacionais, a base institucional de Relações Internacionais na Índia foi reforçada pela difusão de institutos de investigação governamentais e não-governamentais (SHAHI, 2016). Por exemplo, a criação do Indian Council of World Affairs (ICWA) - o primeiro think tank indiano independente sobre relações internacionais - e o jornal India Quarterly foram importantes para o processo de consolidação do campo (BAYLY, 2017, p. $5)$.

${ }^{4}$ De acordo com Behera (2007, p. 344) por duas décadas após a independência, Nehru dominou completamente as análises sobre política externa e relações internacionais; um conhecimento que ficou confinado no Ministério de Relações Exteriores indiano.

${ }^{5}$ A periodização compreende o estabelecimento da Indian Political Science Association - IPSA (1938) e o surgimento de movimentos mais amplos das ciências sociais informados por motivações não-ocidentais e pós-ocidentais na Índia (1969). Bayly (2017) ressalta a importância da IPSA e seu jornal Indian Journal of Political Science aos primeiros anos de formação do campo. Ambas as iniciativas permitiram uma sólida circulação de ideias sobre teoria política e relações internacionais, a
} 
e uma pesquisa aplicada a temas e questões relativas à independência indiana. Nesse caso, a qualidade de ser "primitiva" traduz uma tendência epistemológica específica: nesta, os temas estão profundamente integrados com as preocupações sobre mudanças de posição de poder do Estado indiano no mundo (MALLAVARAPU, 2009; SHAHI, 2016). Em outras palavras, a fase "primitiva" corresponderia aos períodos nos quais houve uma prevalência de estudos de área, enquanto a produção do campo procurou refletir a consolidação da soberania e o caminho do desenvolvimento.

Pela ausência de fatores que permitiriam o aparecimento de uma massa crítica independente capaz de teorizar e complementar o próprio pensamento de Nehru sobre política externa e relações internacionais, nessa primeira fase, houve uma recepção automática do perfil epistemológico anglo-americano. Por um lado, os modelos ocidentais foram adotados pela urgência de querer se achar um princípio de pensamento estruturante para a nação independente, capaz de fomentar, ao mesmo tempo, a inserção do Estado no sistema internacional (MALLAVARAPU, 2009; BAJPAI, 2005). Isso pode parecer ter reforçado obstáculos ao surgimento de uma política de pesquisa orientada à construção de uma disciplina ou um discurso nacional independente em Relações Internacionais (RANA e MISRA, 2004, p. 73; BEHERA, 2007; BAYLY, 2017, p. 7).

Por outro lado, haveria certo número de analistas indianos que desde as origens do campo não se encontram convencidos da necessidade ou utilidade da teoria. Considerada por vezes como muito abstrata ou longe das preocupações locais e regionais para ser estudada com seriedade ou achando-as demasiadamente ocidentais, as teorias sofreram resistências por autores que buscavam compreender, por exemplo, o regionalismo asiático (ACHARYA e BUZAN, 2010, p. 14). Na Índia, no auge da recepção das teorias anglo-americanas, surgiram grupos que saíram em defesa de uma escola nacional. Tal movimento, ao mesmo tempo que não propunha uma crítica às teorias produzidas nos Estados Unidos e Grã-Bretanha, simplesmente assumia a posição: "nós não teorizamos" (BEHERA, 2007, p. 345; BJAPAI, 2005, pp. 25-27).

partir da 1939, na Índia. A IPSA incluía professores de diversas universidades, entre os expoentes, estão B. K. Sarkar, P. N. Sapru, A. Appadorai e Hriday Nath Kunzru (BAYLY, 2017, p. 5). Para Bjapai (2005, p. 25-26), o período de formação do campo compreenderia o período entre as décadas de 50 e 60 , do século XX. 
Se, por um lado, tal resistência possa ser explicada pela existência de barreiras linguísticas, de um modo ou outro, nunca deixou de existir uma maior ou menor infusão de novos estudos e a ampliação do reconhecimento dos parâmetros intelectuais das teorias nessa região do globo (ACHARYA, 2008, pp. 57-59). ${ }^{6}$ Por exemplo, a tendência que apoiava a criação de uma escola nacional foi descartada por autores como A. P. Rana (1980; 1988) K.P. Misra (2005), S. D. Muni e Bajpai (2005, pp. 31-51). Para eles, o caminho não deveria ser de negação das teorias, até porque o problema a ser enfrentado era outro: de inclusão e aceitação do pensamento indiano no Ocidente. Afinal, para esses autores, "nós teorizamos, mas não é reconhecido como teoria" (BEHERA, 2007, p. 345). Recorrer-se à formação de escolas nacionais ou regionais como resistência significava uma postura vulgar e derrotista: o caminho ideal, entre aceitação e crítica, estava num movimento dialógico de ideias. ${ }^{7}$

A verdade é que dentro de um quadro geral, vemos uma heterogeneidade de grupos e posições epistemológicas (BEHERA, 2007, p. 344). Na Índia, a produção do conhecimento divide-se, mais ou menos, por grupos geracionais, a partir dos quais os autores adotam, em diferentes circunstâncias espaço-temporais, perspectivas temáticas, objetos de estudo bem como compreensões distintas sobre a natureza e a função das teorias (CHIMNI e MALLAVARAPU, 2012). Assim, em contraste com a fase "primitiva", a fase "contemporânea" ou a "segunda geração" de estudos do campo (1969 -) qualifica-se pelas preocupações mais moderadas, autoconfiantes e transdisciplinares, adotando postura semelhante aquela defendida acima por A. P. Rana, Bajpai e S. D. Muni. É verdade que os autores da fase

\footnotetext{
${ }^{6}$ De acordo com Acharya, desde o fim da Guerra Fria, as teorias de Relações Internacionais são cada vez mais usadas nas salas de aula e nos estudos sobre relações internacionais asiáticas. Para o autor, o uso crescente da teoria de Relações Internacionais em universidades asiáticas estaria mais ou menos relacionada às práticas internacionais asiáticas. Nesse sentido, a crescente popularidade do liberalismo e do construtivismo naquela região estaria intimamente relacionada com o fim da Guerra Fria e o surgimento de novas instituições regionais na Ásia. Ao mesmo tempo em que eventos conduzem a mudanças no uso ou no desenvolvimento das teorias, em certa medida, as teorias ofereceriam também uma base da racionalização para interpretação dos eventos. Como descreve Acharya, as tensões sino-americanas sobre Taiwan e outras questões de segurança do Leste Asiático deram um novo impulso para o pessimismo realista, enquanto o fim do conflito do Camboja, o Código de Conduta do Mar da China Meridional e o surgimento da Cúpula do Leste Asiático deram um impulso ao otimismo liberal e construtivista (ACHARYA, 2008, pp. 73-76).

7 A "armadilha" de qualquer movimento que procura encontrar aportes culturais e psicológicos próprios para explicar as relações internacionais é o paroquialismo. Geralmente, essa "armadilha" se constitui na defesa de escolas nacionais e regionais, que se tornam, depois, "camisas de força" intelectual e metodológica. Como adiantamos, para Acharya (2011, p. 624), em certo sentido, as escolas nacionais e regionais tornam-se projetos egoístas e até mesmo repressivos.
} 
"contemporânea" não deixam de atuar sobre os efeitos políticos da inserção do Estado e a consolidação da soberania indiana no sistema internacional. E, em certa medida, a pesquisa não deixa ainda de estar vinculada às preocupações com a manutenção da identidade do Estado indiano como "poder ascendente" (RAMAKRISHNAN, 2013).

Porém, é importante reconhecer até que ponto a segunda geração de autores indianos se apresenta circunstanciada por movimentos mais amplos das ciências sociais, ora informados por motivações não-ocidentais / pós-ocidentais / pósestruturalistas. Na verdade, tais autores representam uma parcela de intelectuais da ex-colônia que buscam uma produção acadêmica independente, envolvidos pela problematização do imperialismo acadêmico ocidental, sem ignorar a importância das teorias. ${ }^{8}$ As referências primárias são os autores que surgiram no final da década de 60, o Grupo de Estudos Subalternos, e os expoentes Ranajit Guha, Dipesh Chakrabarty e Gayatri Chakravorty Spivak. Entre as primeiras críticas interdisciplinares, vemos também a importância do Centre for Studies of Developing Societies (CSDS), coordenado por Ashis Nandy, Rajni Kothari, Shiv Visvanathan e Dhirubhai Sheth e o projeto World Order Models Project, desenvolvido no final da década de 60, por Rajni Kothari (BEHERA, 2007, p. 357; KOTHARI, 1979).

Talvez devido ao fato da segunda geração de autores do campo haver se desenvolvido nessa fatia mais recente da teorização pós-estruturalista / pós-colonial / pós-ocidental, é notável perceber como a experiência indiana é mais tolerante com as teorias. Em contraste com a compreensão que aqui fez a "Escola de Brasília", uma característica da abordagem indiana é o respeito pela teoria, ou melhor, a identificação da teoria como vetor emancipatório. Mallavarapu (2009, p. 165), por exemplo, apesar de reconhecer que a teoria, como nós a interpretamos hoje, não ter sido o meio de representação escolhido na Índia antiga, nem por isso ela deveria ser ignorada. Seu papel foi de oferecer termos de conversação com o Ocidente e despertar ansiedades específicas para gerações de estudiosos no país recémdescolonizado. A teoria importa porque, num primeiro momento, ajudou a organizar o campo de estudos na ex-colônia, em seguida, facultou o diálogo com o mundo ocidental, e depois, provocou grande parte do desapontamento que hoje embala

\footnotetext{
${ }^{8}$ De acordo com Behera $(2007$, p. 358 ) a revista Alternatives, lançada em 1975, foi um catalizador e um impulsionador crítico deste movimento, tendo se tornado uma verdadeira "instituição" àqueles que se dedicaram à reflexão e descoberta de novas perspectivas das Relações Internacionais.
} 
uma busca mais sistemática por uma teorização explícita na Índia (MALLAVARAPU, 2009, p. 165).

Nesse sentido, é notável perceber que apesar de existir, na Índia, uma histórica insatisfação com a teoria, tal descontentamento não foi capaz de desencadear em repulsa sistematizada, apesar dos apelos por uma escola nacional, em circunstâncias específicas: pelo contrário, a insatisfação caminhou no sentido de uma identificação em torno de sua insuficiência. Em vez de uma negação compulsiva, essa identificação transformou-se em motivação intelectual que partiu em busca de uma perspectiva de análise teórica diferente, a partir de novas fontes de repertório analítico (ACHARYA, 2011). Se por um lado, tal movimento seja orientado pela identificação de insuficiência das teorias anglo-americanas, por outro lado, procura encontrar o complemento dessa insuficiência na releitura de obras tradicionais. Não se trata da pretensão de corrigir teorias, mas, numa via de mão dupla, trazer ao campo aportes de obras, eventos históricos ou mitológicos indianos e por meio de interpretações alternativas pôr em contato direto com as categorias teóricas, com o propósito de enriquecer o campo $^{9}$ (VIVEKANANDAN, 2011; NARLIKAR E NARLIKAR, 2014; RAJAGOPALAN, 2014).

O caso mais emblemático é a obra de Jayashree Vivekanandan, Interrogating International Relations: India's Strategic Practice and the Return of History (2011). Hoje considerada uma obra pertencente à virada cultural, o texto de Vivekanandan é na verdade uma reação à obra de George Tanhem, Indian Strategic Thought: An Interpretive Essay, publicada em 1992. Tanhem, um acadêmico americano, defendia a tese de que os indianos não tinham pensamento estratégico porque não tinham uma "cultura" estratégica. O que ele queria dizer é que o pensamento cultural indiano, enredado na filosofia kármica e numa lógica circular, incapacitava-os de pensar estrategicamente. O ensaio de Tanhem provocou uma reação acadêmica de amplas proporções que procurou desacreditá-lo, acusando-o de interpretar erroneamente a cultura indiana. Recorrendo à história Hindu e um glorioso passado, os estudos queriam demonstrar que os indianos não só pensavam estrategicamente, mas também tinham uma longa tradição em realpolitik (THAKUR,

\footnotetext{
${ }^{9}$ Segundo Acharya e Buzan (2010, pp. 10-22) podemos dividir as estratégias adotadas em quatro tipos: (i) a utilização de textos tradicionais asiáticos; (ii) o estudo da atuação de líderes asiáticos em política externa; (iii) a adaptação das teorias já existentes à cultura não-ocidental; (iv) o desenvolvimento de novos conceitos.
} 
2012). A questão é que desse modo incidia-se no mesmo erro de Tanhem: defender um "essencialismo indiano" na fronteira do nacionalismo.

A obra de Vivekanandan é um "caminho do meio" entre Tanhem e os estudos de reação. Seu trabalho reapresenta a mentalidade estratégica dos Mogois (15261857) e reintroduz o interessante pensamento político de Akbar assim como descreve as formas de exercício e manutenção de poder deste império, que os leitores poderão ler em sua obra. O que é importante realçar é o esforço exemplar de Vivekanandan de buscar entender uma prática mogol de manutenção de poder visando refletir a noção de soft power, ou seja, uma prática global. Desse modo, o exemplo demonstra algo notável no movimento de teorização indiano. Seus autores de segunda geração não buscam repelir, resistir ou opor-se às categorias teóricas, tampouco defender um essencialismo ou aceitá-las sem críticas: entre o sim e o não, seus esforços atuam no sentido de criar novos espaços de conhecimento e colocar em diálogo com as teorias suas práticas, conceitos culturais e psicológicos, ao mesmo tempo que evitam recorrer ao essencialismo cultural (BEHERA, 2007, p. $341-342) . .^{10}$

Ao dialogar, em vez de repelir, os autores indianos acabam descobrindo novos espaços de conhecimento e com isso problematizando as fontes teóricas. Ao resgatar pensadores e reinterpretar seu patrimônio cultural, percebemos que os indianos revalorizam áreas de conhecimento negligenciados pelos métodos angloamericanos, por exemplo, o campo religioso e espiritual. ${ }^{11}$ Graças a uma herança cultural milenar que vem problematizando dicotomias como matéria/espírito, particular/universal, imanência/transcendência, razão (logos)/tradição (mythos), vemos na Índia um projeto epistemológico verdadeiramente emancipatório, cujo propósito de fundo é repensar as fontes de conhecimento do internacional, facultando ao mesmo tempo uma problematização do estatuto "científico" do campo (ACHARYA, 2011; DAVETAK, 1995).

\footnotetext{
10 Além do trabalho de Vivekanandan, duas pesquisas são consideradas referenciais: a obra de Balmiki Prasad Singh, India's Culture: The State, the Arts, and Beyond (2009) e Regimes of Narcissism, Regimes of Despair, de Ashis Nandy (2013). Nas ciências sociais, ver também Amartya Sen, The Argumentative Indian. Writings on Indian Culture, History and Identity (2005).

${ }^{11}$ É curioso notar como uma teoria na intersecção entre ciência e espiritualidade é plenamente viável, a partir de um contexto indiano. Uma das mais antigas religiões do mundo, o Hinduísmo, e um de seus textos sagrados, o Bhagavad Gita, são um claro exemplo do manancial de possibilidades para a teorização desde a Índia (ACHARYA e BUZAN, 2010; SARKAR, 1919; SEBASTIAN e LANTI, 2010, p. 151-160).
} 
Por exemplo, uma linha de investigação defendida pelos autores indianos envolve a recuperação e a releitura de sua história, de seus mitos, assim como a análise do pensamento político de vários filósofos e pensadores indianos, desde Buda, Iqbal, Valmiki, Manu, Aurobindo Ghosh, Dadabhai Naroji, Rabindranath Tagore e Kautilya (ACHARYA, 2011; BEHERA, 2007, p. 361; BJAPAI, 2005, p. 3031). Aqui, resgate e releitura não são utilizados para substituir as teorias angloamericanas da grade curricular dos cursos de Relações Internacionais, em defesa de um pensamento sem teoria. A intenção não é deslocar o saber existente, mas descobrir novas fontes e contribuir com um diálogo crítico, visando a ampliação da noção do internacional e a construção de teorias alternativas sobre o funcionamento das relações internacionais (ACHARYA e BUZAN, 2010; ACHARYA, 2011).

\section{Considerações finais}

Em termos gerais, o objetivo desse artigo foi buscar apreender, por intermédio de uma análise crítica ao projeto da "Escola de Brasília", as características de um contexto mais amplo e atual de teorização em Relações Internacionais, dentro do qual se insere uma nova geração de autores e trabalhos, que já estão sendo produzidos no Brasil. A discussão da "Escola de Brasília", bem como a análise de suas nuances - enquanto projeto epistemológico -, é decidido, em primeira instância, como representação primária de nosso local de produção de conhecimento e ponto de partida de nosso entendimento global do campo.

Sabemos que uma análise da "Escola de Brasília" não é suficiente e nem poderia sustentar uma argumentação sobre o campo das Relações Internacionais no Brasil como um todo. Aliás, diferentemente da forma como a "Escola" se apresentou em sua origem, ao almejar ser representativa do campo das Relações Internacionais no Brasil, como se fosse uma escola brasileira de Relações Internacionais. Por outro lado, entendemos que o cenário acadêmico e epistemológico das Relações Internacionais no país apresenta peculiaridades e é extremamente complexo.

Por isso mesmo, "provincializar" a experiência de Brasília é a primeira estratégia de leitura. Nessa direção, a comparação com a experiência indiana auxilia a pensar a proposta de Brasília dentro de uma certa divisão global do trabalho intelectual, não passando, portanto, de um percurso entre tantos outros pensados e até mesmo percorridos - no tempo e no espaço - em outros locais de produção de 
conhecimento, seja no país ou no estrangeiro, servindo, desse modo, como exemplificação. Ainda assim, é uma experiência digna de relato, até porque os aspectos locais da experiência humana guardam algo inerente à experiência universal, e desse modo, o local é, não raro, um reflexo de tendências e possibilidades humanas.

Num sentido mais específico, repensar o projeto de Brasília em perspectiva comparada ao desenvolvimento do campo na Índia revelou-se produtivo especialmente porque a comparação realça características que ajudam a intuir, numa apreensão crítica, três dimensões gerais sobre nosso local de trabalho, e numa hipótese mais abrangente, algo sobre o desenvolvimento do campo no Brasil. A comparação (1) destaca problemas na proposta da "Escola de Brasília"; (2) a partir da exemplificação de certa geração indiana das Relações Internacionais, revela métodos de superação dos problemas identificados; (3) sugere que tal processo de superação de problemas já está sendo adotado e debatido como método de teorização por uma nova geração de autores brasileiros localizados em diversas regiões do país.

Em primeiro lugar, os aportes teóricos de certa geração indiana nas Relações Internacionais nos ajudam a realçar ou destacar um pouco melhor os problemas do projeto de Brasília - e consequentemente, a todo e qualquer projeto epistemológico que guarde pretensões e características semelhantes. Conforme vimos, a "Escola de Brasília" para a valorização dos conceitos brasileiros não é efetivamente um movimento descolonizador. Isso é devido, em certa medida, pelo fato desse movimento não haver se inserido no giro decolonial, guardando tendências eurocêntricas na produção do conhecimento e uma postura acrítica sobre a colonialidade na experiência histórica brasileira.

Em segundo lugar - pensando a partir do cenário indiano -, podemos ver que Brasília, além de não representar o quadro geral nacional, ainda se encontra numa fase primitiva de reflexão ao rechaçar o diálogo entre teoria das relações internacionais e os conceitos oriundos do pensamento brasileiro. Isto é, em comparação com as gerações indianas, os autores de Brasília performam uma etapa tradicional de produção do conhecimento, cuja característica central é a busca pela criação de uma escola nacional com rechaço das teorias. Trata-se de uma etapa de teorização que os indianos também experimentaram em circunstâncias específicas. Porém, diferentemente daqui, superaram; aliás, vimos como o debate já está 
bastante aprofundado no campo de Relações Internacionais na Índia. Embora componham um país periférico com passado colonial - tal como o Brasil -, os indianos não adotam a postura defensiva e paroquial de rechaço às teorias com argumento em sua origem anglo-americana. Isso se deve, como notamos, pela ascensão de uma nova geração de autores que, engajados no pós-colonialismo e adeptos a abordagens mais críticas, conseguiram superar uma geração tradicional indiana marcada pela recusa das teorias hegemônicas por uma escola nacional.

Em terceiro lugar, a segunda geração de autores indianos entendeu que o diálogo é necessário e teve disposição e força de vontade de buscar nos arcabouços de sua cultura as ferramentas conceituais para isso. Diferenciam-se exatamente porque são capazes de valorizar sua bagagem cultural para então abrir-se ao diálogo. Entre nós, algo parecido pode ser feito, mas seria decisivo resgatar as matrizes indígena e africana de nosso pensamento, assim como fazem os indianos com referência a seu legado hindu. Essa é uma intuição já presente na obra de Jaguaribe, o qual, apesar de suas limitações, defende uma estratégia de herodianismo seletivo com apoio naquelas matrizes culturais. Como vimos, o trabalho de Urt caminha exatamente nesse sentido, na medida em que contrapõe a visão de mundo dos Guarani e Kaiowá ao paradigma ocidental de soberania.

Desse modo, percebemos que a comparação com a experiência indiana apresentada em termos geracionais projeta nosso próprio contexto de produção do conhecimento, ao realçar e valorizar o trabalho de uma nova geração de autores brasileiros envolvidos cada vez mais com pesquisas inspiradas pelo viés descolonizador e a crítica. No Brasil, existe uma clara, porém difusa disposição geracional, capaz de entender que o pensamento brasileiro e as teorias de relações internacionais podem dialogar criticamente em uma via de mão dupla e fazem isso por meio do resgate e da proposição de novas interpretações da obra de autores clássicos tais como Helio Jaguaribe, Rui Barbosa, Florestan Fernandes e Oswald de Andrade. Vemos um paralelo, uma semelhança à experiência indiana, embora aqui, em comparação à Índia, isso se desenvolva mais tardiamente.

Até certo ponto, nos parece que a estagnação, o desenvolvimento ou a superação de estruturas conceituais dependem de fatores geracionais. A partir do caso indiano, é possível perceber a importância da sucessão geracional e depois o seu compromisso com estudos em contexto, críticos e com efeito descolonizador desde que o propósito não seja eliminar as teorias, mas dialogar criticamente com 
elas, em busca de novos significados para categorias teóricas sedimentadas. Não se trata de pôr um fim ao domínio das teorias, mas de renovar e ampliar o campo. A ideia primordial do movimento indiano, aliás, é a criação de novos espaços de conhecimento nas Relações Internacionais, a partir de um repertório conceitual que tem sido deslegitimado ou considerado irrelevante para a produção de conhecimento na área (BEHERA, 2007; ver também a discussão presente na edição do European Journal of International Relations, vol. 19 [3], de setembro de 2013).

A verdade é que há muitos movimentos na África, no mundo árabe, na Ásia e na América Latina refletindo dentro e fora dessas sociedades (ACHARYA, 2011). Talvez tenha chegado o momento, no Brasil, de refletir sistematicamente esse assunto e buscar criar engajamentos explícitos de nosso patrimônio cultural e intelectual com os eventos e as teorias da política internacional, em busca de um pensamento com teoria. Somente assim podemos contribuir para a diversificação dos termos "global" e "internacional", ampliando as possibilidades de vida e contentamento de viver no mundo contemporâneo.

\section{Referências}

ACHARYA, Amitav. Theoretical perspectives on international relations in Asia. In: SHAMBAUGH, David; YAHUDA, Michael. International Relations of Asia. New York: Rowman \& Littlefield, 2008, pp. 57-82.

Dialogue and Discovery: In Search of International Relations Theory Beyond the West. Millennium: Journal of International Studies, 39 (3), 2011, p. 619637.

ACHARYA, Amitav; BUZAN, Barry. Why is there no non-Western international relations theory? An introduction. In: . (orgs.). Non-Western international relations theory: perspectives on and beyond Asia. London and New York: Routledge, 2010, pp. 1-26.

BALLESTRIN, Luciana. América Latina e o giro decolonial. Revista Brasileira de Ciência Política, no 11. Brasília, maio - agosto de 2013, pp. 89-117.

BAYLY, Martin J. The Forgotten History of Indian International Relations. Observer Research Foundation Issue Brief, no. 210, 2017, pp. 1-8.

BEHERA, Navnita Chadha. Re-imagining IR in India. International Relations of the Asia-Pacific, v. 7, 2007, pp. 341-368. 
BJAPAI, Kanti P. International Studies in India: Bringing Theory (Back) Home. In: ; MALLAVARAPU, Siddhart. International Relations in India. Bringing Theory Back Home. New Delhi: Orient Longman, 2005, pp. 17-38.

CERVO, Amado Luiz. Relações Internacionais do Brasil. In: (org.). 0 desafio internacional: a política exterior de 1930 a nossos dias. Brasília: Editora Universidade de Brasília, 1994, p. 9-58. [2008a]. . Conceitos em Relações Internacionais. Rev. Bras. Polít. Int. 51 (2): 8-25 . Inserção internacional: formação dos conceitos brasileiros. São Paulo: Saraiva, 2008b.

. Amado Luiz Cervo (depoimento, 2017). Rio de Janeiro: CPDOC/Fundação Getúlio Vargas, 2018.

CERVO, Amado Luiz; LESSA, Antônio Carlos. O declínio: inserção internacional do Brasil (2011-2014). Rev. Bras. Polít. Int. 57 (2): 133-151 [2014].

CHIMNI, B.S.; MALLAVARAPU, Siddharth. Indian Thinking in International Relations. In: . (orgs.) International Relations: Perspectives for the Global South. New Delhi: Pearson, 2012.

DAVETAK, R. The project of modernity and international relations theory, Millennium, 24(1), 1995, pp. 27-51.

DUSSEL, Enrique. Transmodernidade e interculturalidade: interpretação a partir da filosofia da libertação. Revista Sociedade e Estado, Volume 31, Número 1, Janeiro/Abril 2016, p. 51-73.

JAGUARIBE, Helio. Estudos filosóficos e políticos. Coleção Helio Jaguaribe. Brasília: FUNAG, 2013.

JATOBÁ, Daniel. Los desarollos académicos de las Relaciones Internacionales en Brasil: elementos sociológicos, institucionales y epistemológicos. Relaciones Internacionales, número 22, febrero - mayo 2013 (a), Grupo de Estudios de Relaciones Internacionales (GERI) - Universidad Autónoma de Madrid, España, p. 27-46.

. Repensar y rehacer la realidad contemporánea tras la expansión filosófica de las Relaciones Internacionales. Relaciones Internacionales, número 24, octubre 2013 (b) - enero 2014, Grupo de Estudios de Relaciones Internacionales (GERI) Universidad Autónoma de Madrid, España, p. 109-127.

KOTHARI, R. Towards a just world, Alternatives, 5(1), 1979, pp. 1-42.

LAGE, Victor Coutinho. Interpretations of Brazil and Global Capitalism. Latin American Perspectives, Issue 227, Vol. 46, No. 4, July 2019, p. 137-153. 
LAPID, Yosef. The Third Debate: On The Prospects of International Theory in a PostPositivist Era. International Studies Quarterly, Vol. 33, No. 3 (Sept., 1989), p. 235254.

LESSA, Antônio Carlos. O ensino de Relações Internacionais no Brasil. In: SARAIVA, José Flávio Sombra; CERVO, Amado Luiz (orgs.). O crescimento das Relações Internacionais no Brasil. Brasília: Instituto Brasileiro de Relações Internacionais (IBRI), 2005, p. 33-50.

LISLE, Debbie. Waiting for International Political Sociology: a field guide to living inbetween. International Political Sociology (2016) 10, 417-433.

LUCIANO, Bruno Theodoro. Abstrações imperfeitas: o uso de teorias e de conceitos em Relações Internacionais. Século XXI, Porto Alegre, V. 4, No. 1, Jan-Jun 2013, p. 73-88.

MALLAVARAPU, Siddharth. Development of International Relations Theory in India: Traditions, Contemporary Perspectives and Trajectories, International Studies, v. 46, 2009, pp. 165-183.

MIGNOLO, Walter D. Delinking: the rhetoric of modernity, the logic of coloniality and the grammar of de-coloniality. Cultural Studies, Vol. 21, Nos. 2-3, March/May 2007, p. 449-514.

MUÑOZ, Luciano da Rosa. O conceito de autonomia em Puig e Jaguaribe: uma análise comparativa intertextual. Carta Internacional, v. 11, p. 200-221, 2016.

. Intelectuais, militares, diplomatas: uma genealogia da autonomia no Brasil (1946-1974). Tese (Doutorado em Relações Internacionais), Universidade de Brasília, Brasília, 2019.

NANDY, Ashis. Regimes of Narcissism, Regimes of Despair. Oxford: Oxford University Press, 2013.

NARLIKAR, Amrita; NARLIKAR, Aruna. Bargaining with a Rising India: Lessons from the Mahabharata. Oxford: Oxford University Press, 2014.

ORTEGA Y GASSET, José. El tema de nuestro tiempo (1923). In: ORTEGA Y GASSET, José. Obras completas. Tomo III (1917-1928). Sexta edición. Madrid: Revista de Occidente, 1966, p. 143-242.

QUIJANO, Aníbal. Colonialidad y Modernidad/Racionalidad. Perú Indígena, 13 (29), 1992, p. 11-20.

. Coloniality of Power, Eurocentrism, and Latin America. Nepantla: Views from South, 1.3, 2000, p. 533-580.

RAJAGOPALAN, Swarna. Grand Strategic Thought in the Ramayana and Mahabharata. In: BJAPAI, Kanti; BASIT, Saira; KRISHNAPPA, V. (orgs.) India's Grand Strategy: History, Theory, Cases. New Delhi: Routledge, 2014. 
RAJAN, M.S. (org.) International and Area Studies in India. New Delhi: Lancer Books, 1997.

RAMAKRISHNAN, A. K. Normative Dimensions of India's International Engagement. In: VANAIK, Achin; BEHERA, Navnita (orgs.) India Engages the World (ICSSR Research Survey in Political Science). New Delhi e Oxford: Oxford University Press, 2013, pp. 153-196.

RANA, A.P. The Development of International Studies in India: A Profile of Some Critical Constraints. In: MISRA, K.P.; BEAL, R.C. (orgs.). International Relations Theory: Western and Non-Western Perspectives. New Delhi: Vikas Publishing House, 1980, pp. 228-239.

- Reconstructing International Relations as a Field of Study in India: A Program for the Disciplinary Development of International Relations Studies. Studying International Relations, The Baroda Perspective, Occasional Review-I. Baroda: The Maharaja Sayajirao University, 1988.

RANA, A.P.; MISRA, K.P. Communicative Discourse and Community in International Relations Studies in India: A Critique. In: BJAPAI, Kanti; MALLAVARAPU, Siddhart (orgs.) International Relations in India. Bringing Theory Back Home. New Delhi: Orient Longman, 2005, pp. 71-122.

SAHNI, Varun. The Fallacies and Flaws of Area Studies in India. International Studies. v. 46, 2009, pp. 49-68.

SARAIVA, José Flávio Sombra. História das relações internacionais: o objeto de estudo e a evolução do conhecimento. In: . (org.). História das Relações Internacionais Contemporâneas: da sociedade internacional do século XIX à era da globalização. São Paulo : Saraiva, 2008, p. 7-40.

Autonomia na Inserção Internacional do Brasil: Um Caminho Histórico Próprio. Contexto Internacional, Rio de Janeiro, vol. 36, n 1, janeiro/junho 2014, p. 9-41.

SARKAR, B.K. Hindu Theory of International Relations. American Political Science Review, v. 13, no. 3, 1919, pp. 400-414.

SEBASTIAN, Leonard C; LANTI, Irman G. Perceiving Indonesian approaches to international theory. In: ACHARYA, Amitav; BUZAN, Barry (orgs.) Non-western international relations theory. Perspectives on and beyond Asia. London: Routledge, 2010, pp. 148-173.

SELIS, Lara Martim Rodrigues. Infiltração clandestina: a questão da diferença no pensamento latino-americano. Rev. Carta Inter., Belo Horizonte, v. 13, n. 2, 2018, p. 171-194.

SEN, Amartya. The Argumentative Indian. Writings on Indian Culture, History and Identity, London: Penguin Books, 2005.

SHAHI, Deepshikha. Teaching International Relations in India: from pedagogy to andragogy. E-international relations. Disponível em: http://www.e- 
ir.info/2016/10/29/teachinginternational-relations-in-india-from-pedagogy-toandragogy/ Acessado em 12 de setembro de 2019.

SINGH, Balmiki Prasad. India's Culture: The State, the Arts, and Beyond. Oxford: Oxford University Press, 2009.

SPIVAK, Gayatri Chakravorty. Pode o subalterno falar? Tradução de Sandra Regina Goulart Almeida, Marcos Pereira Feitosa e André Pereira Feitosa. Belo Horizonte: Editora UFMG, 2010.

SPODE, Raphael. An Inquiry into the Moral and Religious Dimensions of International Politics: the Thought and Contribution of Rui Barbosa. Contexto Internacional, vol. 39 (1), Jan/Abr 2017, p. 53-73.

TANHAM, George K. Indian Strategic Thought. An Interpretative Essay. California: National Defense Research Institute (RAND), 1992.

THAKUR, Vineet. India's Strategic Practice and the Return of History. E-international relations. Disponível em: https://www.e-ir.info/2012/01/23/review-indias-strategicpractice-and-the-return-of-history/ Acessado em 13 de setembro de 2019.

URT, João Nackle. How Western Sovereignty Occludes Indigenous Governance: the Guarani and Kaiowa Peoples in Brazil. Contexto Internacional, vol. 38 (3) Sep/Dec 2016, p. 865-886.

VIVEKANANDAN, Jayshree. Interrogating International Relations: India's Strategic Practice and the Return of History. New Delhi. Routledge, 2011.

WÆVER, Ole. The Sociology of a Not So International Discipline: American and European Developments in International Relations. International Organization, 52 (4), Autumn 1998, p. 687-727.

WALKER, R. B. J. Realism, Change, and International Political Theory. International Studies Quarterly, Vol. 31, No. 1 (Mar., 1987), p. 65-86.

WALTZ, Kenneth. Theory of International Politics. New York: Random House, 1979. 